\title{
Induction of secretory acid proteinase in Candida albicans
}

\author{
Anasua BanerJee, K. Ganesan and Asis Datta* \\ Molecular Biology Laboratory, School of Life Sciences, Jawaharlal Nehru University, New Delhi 110067, India
}

(Received 6 February 1991; revised 28 May 1991; accepted 19 June 1991)

\begin{abstract}
Candida albicans and some other pathogenic Candida species, when grown in a medium containing a protein as a sole source of nitrogen, secrete an acid proteinase. Culture supernatants were assayed for proteinase activity, and were also analysed by Western blotting with antibodies raised and affinity-purified against proteinase of $C$. albicans. Proteinases secreted by $C$. tropicalis and $C$. parapsilosis were antigenically related to that of $C$. albicans, but had different molecular masses. The proteinases secreted by $C$. lipolytica, $C$. rugosa and $C$. lusitaniae were not antigenically related. The kinetics of proteinase secretion by $C$. albicans were monitored by activity and by Western blotting. With BSA as the nitrogen source, proteinase secretion increased exponentially until about $16 \mathrm{~h}$. Culture supernatants of BSA-grown cultures accumulated proteinase to about a 1000-fold higher level than those of ammonium-sulphate-grown cultures. In vivo labelling experiments showed that proteinase was not detectably accumulated in the cells, but was secreted immediately after synthesis. Immunoprecipitation of in vitro translated poly(A)-containing RNA identified a putative pre-protein of about $54 \mathrm{kDa}$. As well as BSA, other proteins (haemoglobin, ovalbumin, histone), peptone and tryptone, when used as nitrogen sources, could induce proteinase, but to different levels. When Casamino acids or an amino acid mixture (equivalent to the composition of BSA) was used as nitrogen source, no induction was observed. Ammonium sulphate, or any other ammonium salt, repressed secretion of proteinase.
\end{abstract}

\section{Introduction}

Candida albicans is recognized as the most important pathogenic yeast, causing candidosis in immunocompromised humans and other warm-blooded animals. There has been an increasing incidence of candidosis in the last two decades, attributed to the widespread use of antibiotics and immunosuppressive agents (Odds, 1988). Among various hydrolytic enzymes reported as possible virulence factors in the pathogenicity of $C$. albicans, secretory acid proteinase has gained substantial importance, and its significance in candidosis has been studied by several groups (Staib, 1969; Remold et al., 1968; Ruchel, 1981; MacDonald \& Odds, 1980; Ray and Payne, 1990). The physiology of induction of secretory acid proteinase in $C$. albicans, under one set of conditions, has been studied by Ross et al. (1990). The ability of other species of Candida to secrete proteinases, and the immunological relatedness of these proteinases has also been reported (Ruchel et al., 1983, 1986).

Using a very sensitive assay for proteinase, and Western blot analysis employing affinity-purified anti-

Abbreviations: CS, culture supernatant; AS, ammonium sulphate. proteinase antibodies, we studied proteinase secretion by different Candida species, and the immunological relationships of these proteinases to that of $C$. albicans. We also studied the kinetics of proteinase induction in $C$. albicans, and induction by different proteins, peptone and tryptone. A putative pre-protein of proteinase was identified by in vitro translation of RNA isolated from induced cells and immunoprecipitation.

\section{Methods}

Organisms and growth conditions. C. albicans SC5314 was obtained from Dr D. R. Kirsch (Squibb Institute of Medical Research, Princeton, New Jersey, USA). C. albicans ATCC 10261 was obtained from Dr M. G. Shepherd (University of Otago, Dunedin, New Zealand), C. tropicalis 3113 and $3118, C$. parapsilosis $3323, C$. rugosa 3467 , C. lusitaniae 3484, C. lipolytica 3229, C. utilis 3469, C. krusei 3518 , $C$. shehetae 2500 and $C$. guilliermondii 3126 were obtained from the National Collection of Industrial Microorganisms (NCL, Pune, India). These were maintained on YPD-agar $[1 \%(w / v)$ yeast extract (Difco), $2 \%(\mathrm{w} / \mathrm{v})$ peptone, $2 \%(\mathrm{w} / \mathrm{v})$ glucose and $2 \%(\mathrm{w} / \mathrm{v})$ agar]. For all experiments, peptone from Glaxo (India) was used, unless otherwise mentioned. All minimal media contained $0.17 \%$ yeast nitogen base without amino acids and without ammonium sulphate (Himedia, Bombay, India) and $2 \%(w / v)$ glucose (autoclaved); to this, either 
ammonium sulphate (AS) or BSA was added to a final concentration of $0.2 \%$ from $4 \%(\mathrm{w} / \mathrm{v})$ filter-sterilized (BSA) or autoclaved (AS) stock solution. When a mixture of three amino acids $(1 \mathrm{mg}$ histidine- $\mathrm{HCl}$, $2 \mathrm{mg}$ DL-methionine and $2 \mathrm{mg}$ DL-tryptophan per litre) was added to the above media, they are referred to as MI-AS or M1-BSA; otherwise they are referred to as M2-AS or M2-BSA. A loopful of yeast cells from freshly prepared YPD-agar slants was grown in liquid YPD medium at $30{ }^{\circ} \mathrm{C}$ with shaking for $14 \mathrm{~h}\left(\mathrm{OD}_{595}\right.$ reached approximately $\left.9 \cdot 0\right)$. This preculture was diluted to $1 \%(\mathrm{v} / \mathrm{v})$ in experimental media, and incubated at $30^{\circ} \mathrm{C}$ on a gyratory shaker at about 200 r.p.m. Cell number was calculated from $\mathrm{OD}_{595}$ calibrated using a haemocytometer. Buds were counted as separate cells.

Proteinase assays. Proteinase activity was checked either by milk agarose spot assay or spectrophotometrically. The composition of milk agarose was $1 \%(\mathrm{w} / \mathrm{v})$ agarose, $1 \%(\mathrm{w} / \mathrm{v})$ skim milk powder, and $0.114 \mathrm{M}$-sodium acetate, pH 5.3 (Foltmann et al., 1985). Culture supernatants (CS) or their dilutions, $(5 \mu \mathrm{l}$ each) were spotted on the milk agarose plate. Doubling dilutions of purified proteinase or CS of fully induced BSA broth were spotted to serve as standards. The plate was covered with Saran wrap and incubated at room temperature. Proteinase activity was seen as a white spot due to clotting of casein. The diameter of spots of standards and samples were measured after 6 to $24 \mathrm{~h}$ incubation at room temperature. A linear relationship was obtained when the diameter (linear scale) was plotted against the amount of enzyme (logarithmic scale), from which the amount of enzyme in unknown samples was calculated (Schumacher \& Schill, 1972). In the spectrophotometric assay, proteinase activity was determined by the extent of digestion of BSA at pH 3.6, which was derived from the amount of TCA-soluble material found after incubation of BSA with proteinase (Shimizu et al., 1987). A change of one $A_{280}$ unit in $30 \mathrm{~min}$ at $37^{\circ} \mathrm{C}$ was taken as one unit of enzyme activity.

Purification of proteinase. Secretion of proteinase was induced by growing $C$. albicans SC5314 in M1-BSA. The proteinase was purified by a modified method of Shimizu et al. (1987). About $850 \mathrm{ml} \mathrm{CS}$, after

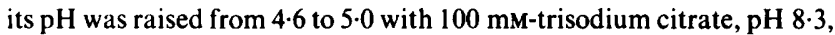
was applied to a DE52 column $(1.5 \times 29 \mathrm{~cm})$ which had been equilibrated with $10 \mathrm{~mm}$-sodium citrate, $\mathrm{pH} 5.0$ (Buffer A). After the column was washed with one bed volume of buffer $A$, it was eluted with a linear gradient of 0 to $1 \mathrm{M}-\mathrm{KCl}$ in buffer $\mathrm{A}$. Fractions displaying activity were pooled, dialysed against buffer $\mathrm{A}$, and bound to a DEAESepharose CL-6B column $(1 \times 15 \mathrm{~cm})$ equilibrated in the same buffer. Proteinase was eluted by a decreasing $\mathrm{pH}$ gradient generated by passing an acidic buffer ( $4 \mathrm{mM}$ each of DL-aspartic acid, L-glutamic acid and glycine, $\mathrm{pH} 2.6$ ) through the column. The proteinase was purified to apparent homogeneity as assessed by SDS-PAGE using the discontinuous buffer system of Laemmli (1970). It had a specific activity of over $100 A_{280}$ units (mg protein) $)^{-1}$.

Affinity purification of anti-proteinase antibodies. Antibodies were raised against purified proteinase in a rabbit. Affinity purification was done essentially as described by Iwaki et al. (1989). The purified

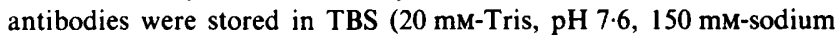
chloride) containing $0.1 \% \mathrm{NaN}_{3}$, at $4{ }^{\circ} \mathrm{C}$. For Western blot analysis (Towbin et al., 1979) these antibodies were used at 1:900 dilution in TBST (TBS with $0 \cdot 05 \%$ Tween 20 ). Immunodetection was done using the protoblot alkaline phosphatase system (Promega).

RNA Isolation. RNA was isolated by a modified method of Chomczynski \& Sacchi (1987). The modifications were: (1) a higher concentration $(1.25 \times)$ of solution $D$ was used to process more cells in a smaller volume; (2) glass beads were used to break the cells; and (3) the final RNA pellet was washed in $3 \mathrm{M}$-sodium acetate, $\mathrm{pH} 5 \cdot 5$, to remove any DNA contaminants (Hereford \& Rosbash, 1977). Poly (A)+ RNA was isolated by one cycle of purification on oligo(dT)-cellulose column as described by Maniatis et al. (1982), except that SDS was omitted from all the buffers, and before eluting the bound RNA, the column was washed only with column loading buffer $(20 \mathrm{~mm} \mathrm{Tris} / \mathrm{HCl}, \mathrm{pH} \mathrm{7.6}$, $0.5 \mathrm{M}-\mathrm{NaCl}$ and $1 \mathrm{~mm}-\mathrm{EDTA}$ ).

In vivo labelling and immunoprecipitation. To check the specificity of immunoprecipitation, an M2-BSA grown culture $(10 \mathrm{~h})$ of $C$. albicans strain SC5314 was labelled in vivo with $50 \mu \mathrm{Ci}(1.85 \mathrm{MBq}) \mathrm{ml}^{-1}$ of $\left[{ }^{35} \mathrm{~S}\right]-$ methionine $\left(>800 \mathrm{Ci}\left(2.96 \times 10^{13} \mathrm{~Bq} \mathrm{mmol}-1\right.\right.$, Amersham $)$ for $20 \mathrm{~min}$. The labelling reaction was stopped by adding TCA to $10 \%$ $(w / v)$ final concentration. For pulse-chase, $100 \mu \mathrm{Ci}\left[{ }^{35} \mathrm{~S}\right]$ methionine was added to $1 \mathrm{ml} \mathrm{M2-BSA}$ culture and incubated for $4 \mathrm{~min}$. Then unlabelled methionine was added to a final concentration of $200 \mu \mathrm{g} \mathrm{ml}^{-1}$ to initiate the chase. Samples were taken out at different time intervals, added to prechilled Eppendorf tubes and centrifuged immediately. For preparation of crude extracts, pellets were ground with glass beads $(0.3 \mathrm{~g}$ glass beads $(0.45 \mathrm{~mm})$ to $0.1 \mathrm{~g}$ pellet $)$ in $0.3 \mathrm{ml}$ grinding buffer (50 mM-Tris/HCl, pH 8.0, 1 mM-EDTA, 1 mM-PMSF and $1 \mathrm{~mm}-\beta$-mercaptoethanol), by vortexing for $6 \mathrm{~min}$, in $1 \mathrm{~min}$ bursts, with cooling on ice in between. Crude extracts prepared in this way and supernatants were processed separately for immunoprecipitation.

For immunoprecipitation, the method of Anderson \& Blobel (1983) was essentially followed. Preadsorption of antibodies to protein ASepharose beads was done as described by Kessler (1981), and preclearing was done as described by Ausubel et al. (1987). The immunoprecipitates were resolved by SDS-PAGE, and radiolabelled bands were detected by fluorography (Chamberlain, 1979).

Inducers other than BSA. Haemoglobin, ovalbumin, histone, peptone, tryptone, Casamino acids $[4 \%(\mathrm{w} / \mathrm{v})$ stock in water], and amino acid mixture $[2 \%(w / v)$ stock, equivalent to composition of BSA] were each added separately to $M 2$ medium at $0 \cdot 2 \%$ final concentration as a sole nitrogen source. At various times, CS was collected and analysed by milk agarose spot assay and by Western blot.

\section{Results and Discussion}

\section{Proteinase secretion by Candida species}

Proteinase secretion by various medically important Candida species and $S$. cerevisiae was determined by milk agarose spot assay (Fig. 1). This assay can detect less than $1 \mathrm{ng}$ of proteinase, and it is about 100 -fold more sensitive than the spectrophotometric assay (unpublished results). Most of the pathogenic Candida species (C. albicans, C. tropicalis, $C$. parapsilosis, C. rugosa, $C$. lusitaniae, $C$. lipolytica) secreted proteinase when grown with BSA as a nitrogen source. C. utilis, C. krusei, $C$. shehatae and $S$. cerevisiae did not show any activity (Fig. 1). Culture supernatants of all these species were also analysed by immunoblotting with $C$. albicans antiproteinase antibodies. Proteinase of $C$. tropicalis and $C$. parapsilosis were antigenically related to that of $C$. albicans (Fig. 2). However, the apparent molecular mass of proteinase secreted by $C$. albicans was $45 \mathrm{kDa}$, whereas that of $C$. tropicalis was $49 \mathrm{kDa}$ and that of $C$. parapsilosis $36 \mathrm{kDa}$ (Fig. 2). The secretory acid proteinases of these three species have been found to be related, 


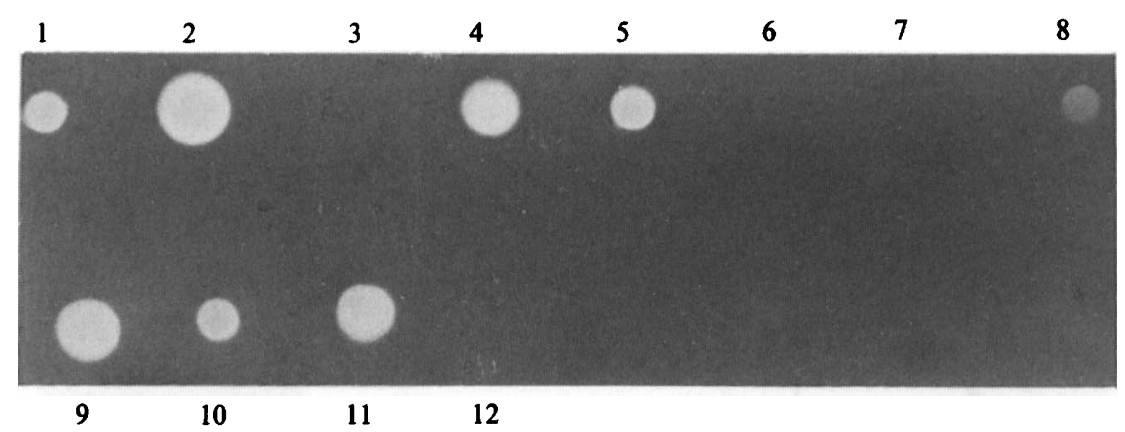

Fig. 1. Milk agarose spot assay for secretory acid proteinase. Different strains were grown in BSA broth for $48 \mathrm{~h}$, and $5 \mu \mathrm{l}$ of the culture supernatants were spotted on a milk-agarose plate and incubated at room temperature for $6 \mathrm{~h}$. Diameter of the spots indicates proteinase level. The yeast strains used were 1 , C. albicans $3466 ; 2$, C. albicans $3471 ; 3$, C. krusei $3518 ; 4$, C. lusitaniae $3484 ; 5, C$. rugosa $3467 ; 6$, C. utilis $3469 ; 7$, C. shehatae $3500 ; 8$, C. guilliermondii $3126 ; 9$, C. lipolytica $3229 ; 10$, C. parapsilosis $3323 ; 11$, C. tropicalis 3118 ; and 12 , Saccharomyces cerevisiae 3511.

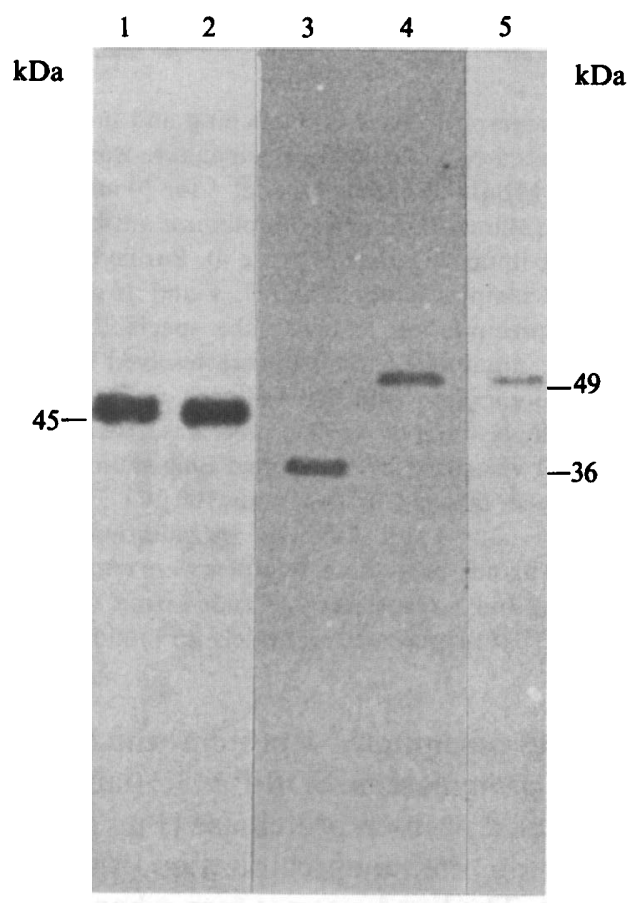

Fig. 2. Western blot analysis of culture supernatants of various yeast strains grown in BSA broth. Affinity-purified anti-proteinase antibodies raised against $C$. albicans proteinase were used. Lanes: $1, C$. albicans SC5314; 2, C. albicans $10261 ; 3, C$. parapsilosis, 3323; 4, C. tropicalis $3118 ; 5$, C. tropicalis 3113 .

partially related, or unrelated, depending on the antiserum employed (Ruchel et al., 1983, 1986). Among pathogenic Candida species, C. albicans and C. tropicalis are considered to be very similar, and $C$. parapsilosis as the next most similar (Odds, 1988). This view is further strengthened by our Western blot data.

\section{Kinetics of proteinase induction in $C$. albicans}

A YPD preculture of $C$. albicans strain SC5314 was diluted into M1-AS or M1-BSA, and incubated as described in Methods. If the YPD culture was washed and inoculated into these media, proteinase secretion was delayed by over $24 \mathrm{~h}$. The level of proteinase in CS was determined by milk-agarose spot assay. No proteinase was detected in CS of M1-AS, though C. albicans grew better in M1-AS until about $16 \mathrm{~h}$, as compared to M1-BSA. The proteinase level in CS of M1-BSA increased exponentially until $16 \mathrm{~h}$ (Fig. 3), after which it remained constant for at least $24 \mathrm{~h}$ (data not shown); most of the proteinase was secreted between 10 to $16 \mathrm{~h}$. Proteinase secretion was also checked by Western blot analysis. In spite of the greater sensitivity of this method, no proteinase was detected in CS of M1-AS (Fig. 4). The degradation seen in the last two lanes of M1-BSA culture was insignificant, since proteinase level, in terms of activity, remained constant for several more hours. Since Western blot analysis is an extremely sensitive technique, it can detect degradation products present in subnanogram amounts. When fully induced, proteinase accumulated in M1-BSA culture to about a 1000-fold higher level than in M1-AS culture, since, in a Western blot, the proteinase band was seen at 1024-fold dilution of the CS of the former, but it was not detected even in the undiluted CS of the latter (data not shown). Under a different set of inducing conditions, proteinase level in the CS initially increased rapidly, decreased later, and then increased again (Ross et al., 1990). Under our conditions, the proteinase level remained constant until at least $24 \mathrm{~h}$ from the highest level of proteinase reached at $16 \mathrm{~h}$. The variation in the pattern of induction might be due to the different inducing conditions employed.

Proteinase secretion was also studied by in vivo labelling and immunoprecipitation. The affinity-puri- 


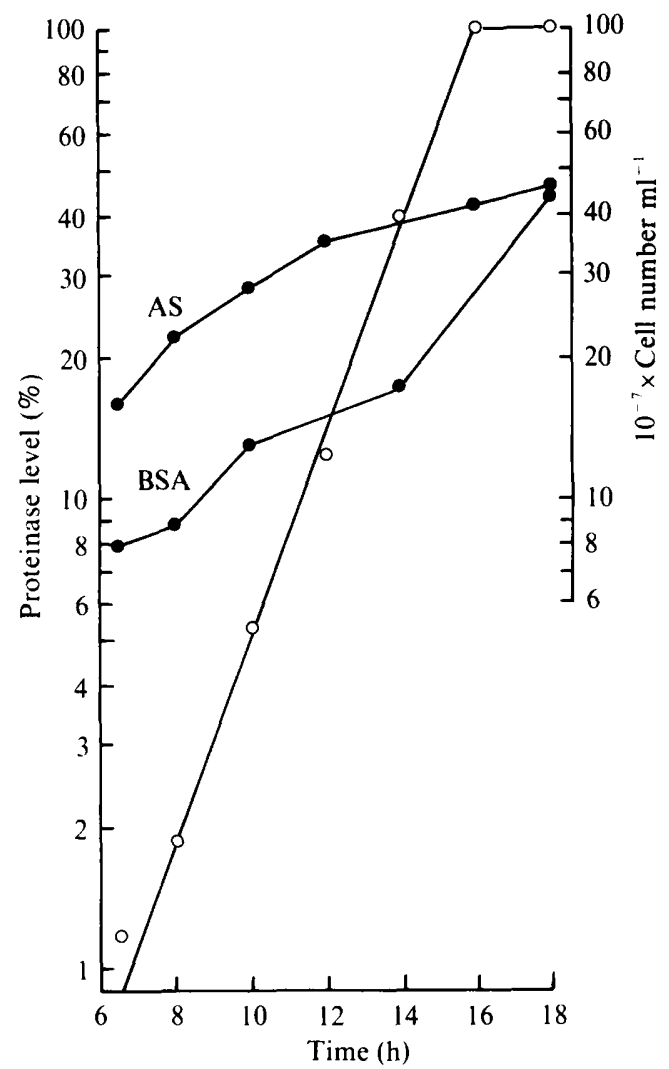

Fig. 3. Kinetics of proteinase secretion. A $14 \mathrm{~h}$ YPD culture of $C$. albicans strain SC5314 was diluted 100-fold in M1-AS or M1-BSA. Cell number $(O)$ and proteinase level $(O)$ (by milk agarose spot assay) were determined at different times. CS from M1-AS did not show any proteinase activity. The proteinase level is expressed as a percentage of the level at $18 \mathrm{~h}$, after which there was no further increase.

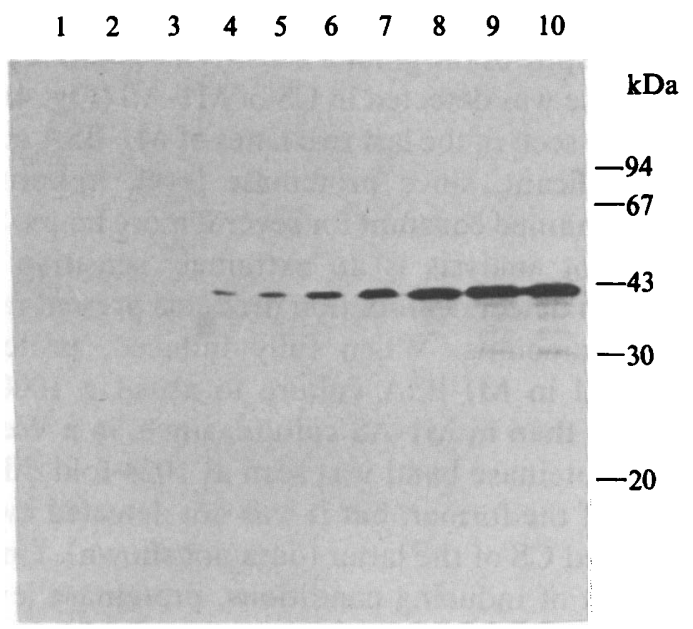

Fig. 4. Kinetics of proteinase secretion by Western blot analysis. Culture supernatant ( $16 \mu \mathrm{l}$ each) of $C$. albicans strain SC5314, grown with either M1-AS (lanes 1 to 3) or MI-BSA (lanes 4 to 10), were resolved on a 10 to $17 \%(w / v)$ gradient SDS-PAGE, transferred to nitrocellulose and probed with affinity-purified anti-proteinase antibodies. CS of M1-AS cultures was collected at $6.5 \mathrm{~h}$ (lane 1), $14 \mathrm{~h}$ (lane 2) and $18 \mathrm{~h}$ (lane 3), and that of M1-BSA culture at $6.5 \mathrm{~h}$ (lane 4 ), $8 \mathrm{~h}$ (lane 5), $10 \mathrm{~h}$ (lane 6), $12 \mathrm{~h}$ (lane 7), $14 \mathrm{~h}$ (lane 8), $16 \mathrm{~h}$ (lane 9) and $18 \mathrm{~h}$ (lane 10).

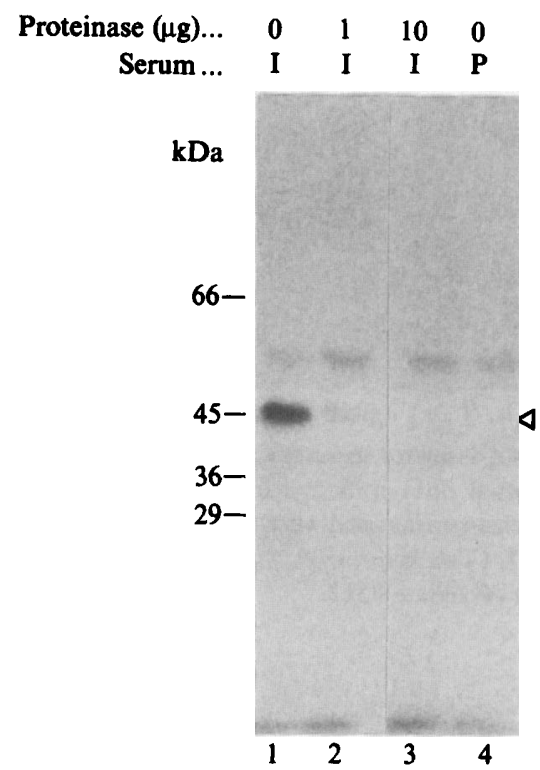

(a)

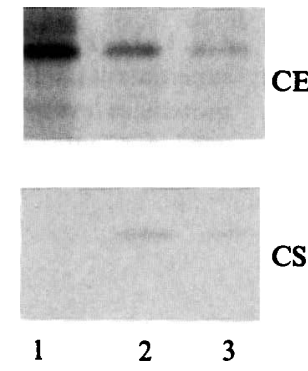

(b)
Fig. 5. Autoradiograph from in vivo labelling and immunoprecipitation of BSA-induced cells. (a). BSA-grown culture was labelled in vivo with $50 \mu \mathrm{Ci}(1.9 \mathrm{MBq})\left[{ }^{35} \mathrm{~S}\right]$ methionine $\mathrm{ml}^{-1}$ for $20 \mathrm{~min}$ and immunoprecipitated with affinity-purified anti-proteinase antibodies $(I$; lanes 1 to 3 ) or with pre-immune serum (P; lane 4$)$. Purified proteinase was included in two samples (lanes 2 and $3 ; 1$ and $10 \mu \mathrm{g}$, respectively) during immunoprecipitation to check the specificity of the signal lighting up. The immunoprecipitates were resolved by SDS-PAGE, processed for fluorography and exposed to X-ray film. Open arrow head indicates the position of purified proteinase, which was run in a parallel lane and visualized by Coomassie Blue staining. (b) A BSAgrown culture was labelled in vivo with $100 \mu \mathrm{Ci}(3.7 \mathrm{MBq})\left[{ }^{35} \mathrm{~S}\right]-$ methionine $\mathrm{ml}^{-1}$ for $4 \mathrm{~min}$ followed by addition of unlabelled methionine $\left(200 \mu \mathrm{g} \mathrm{ml}^{-1}\right)$ for chase. Samples were removed at 0,8 and 16 min (lanes 1, 2 and 3, respectively). Crude extract (CE) and culture supernatants (CS) were processed separately for immunoprecipitation.

fied antibodies precipitated a protein which comigrated with purified proteinase on SDS-PAGE (lane 1, Fig. 5a). When unlabelled purified proteinase $(1 \mu \mathrm{g}$ or $10 \mu \mathrm{g})$ was included during immunoprecipitation, the band was competed out. The band was not seen when pre-immune serum was used as a control (lane 4, Fig. 5a). These results show that the immunoprecipitated protein was proteinase. Furthermore, in a pulse chase experiment we found that the proteinase band intensity in crude cell extracts fell rapidly, while that in CS increased, showing that proteinase synthesis and secretion were coupled, and that proteinase was not accumulated in the cells (Fig. $5 b$ ). Ross et al. (1990) have also concluded, by Western blot analysis of crude extracts of induced cells, that there was no intracellular accumulation of proteinase.

\section{Evidence for pre-proteinase}

Secreted proteins are normally translated in vivo as larger precursors which are processed to a smaller size during 

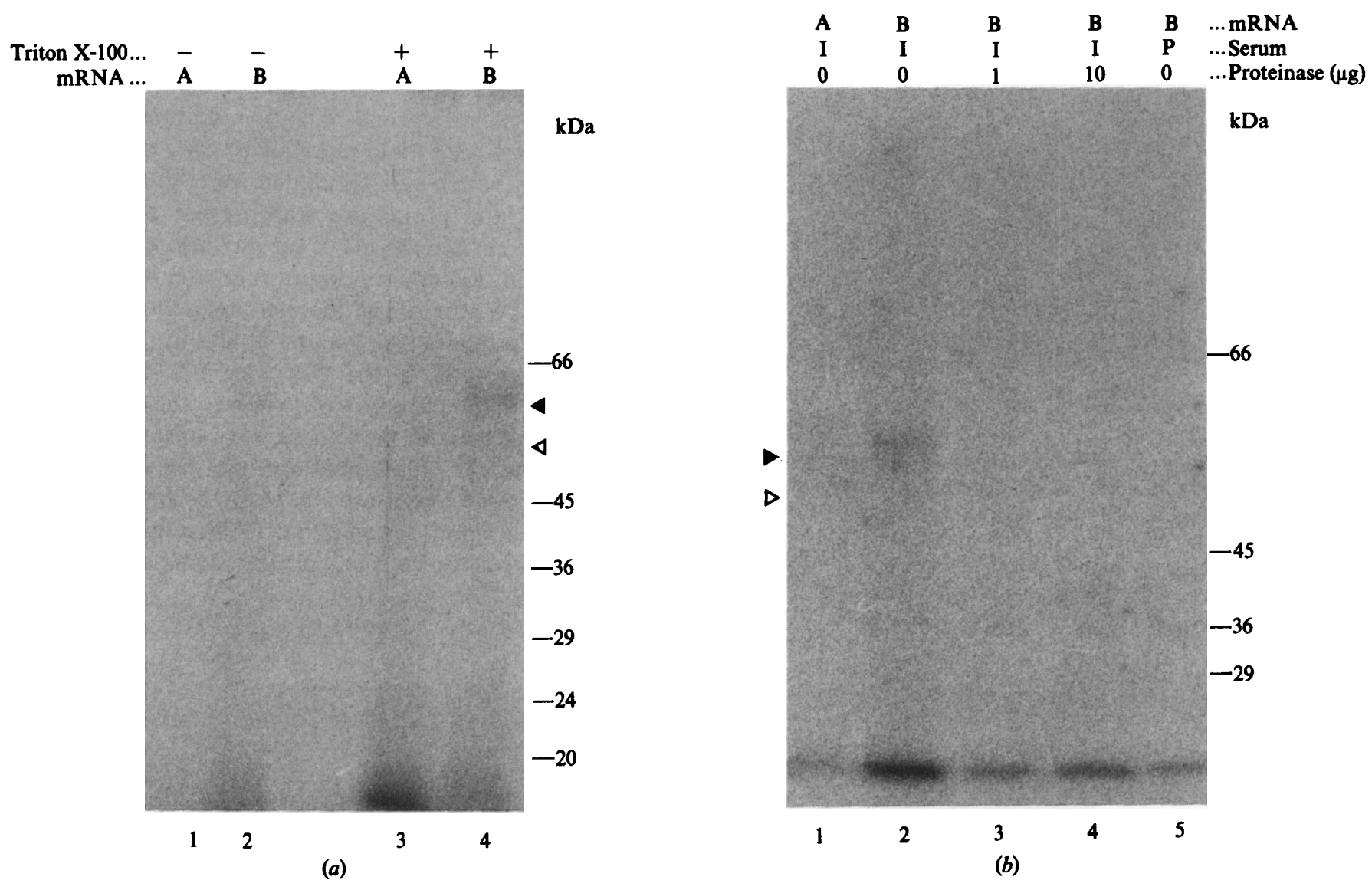

Fig. 6. Autoradiograph from immunoprecipitation of in vitro translated products. (a) mRNAs from uninduced (A, ammonium sulphate grown; lanes 1 and 3) and induced (B, BSA grown; lanes 2 and 4) cultures were translated in retic lysate with (lanes 3 and 4 ) or without (lanes 1 and 2) Triton X-100, immunoprecipitated with affinity-purified anti-proteinase antibodies, analysed by SDS-PAGE and processed for fluorography. Closed arrow head indicates the position of pre-protein seen in lanes 2 and 4 . Open arrow head corresponds to the purified proteinase which was run in a parallel lane and visualized by Coomassie Blue staining. (b) mRNAs purified from uninduced ( $A$, lane 1$)$ and induced (B, lanes 2 to 5 ) cultures were translated in the presence of Triton $X-100$, in retic lysate, and immunoprecipitated with immune (I, lanes 1 to 4 ) or pre-immune (P, lane 5) serum. Purified proteinase was included in two samples (lanes 3 and 4,1 and $10 \mu \mathrm{g}$, respectively) during immunoprecipitation to check the specificity of the band lighting up.

secretion (Randall et al., 1987). To determine the size of the precursor form of the C.albicans proteinase, mRNAs isolated from induced and uninduced cells were translated in reticulocyte lysate and immunoprecipitated. The pre-proteins are not processed in the lysate system. In some experiments, Triton $\mathrm{X}-100$, which stimulates translation of secreted proteins (Nash \& Tate, 1984), was included. An immunoprecipitated $54 \mathrm{kDa}$ band, specifcally translated from BSA-induced RNA, was more intense in the presence of Triton X-100 (Fig. $6 a$ ). This $54 \mathrm{kDa}$ band could be the precursor of proteinase. To test whether it was related to proteinase, purified unlabelled proteinase was included during immunoprecipitation as a competitor. If the $54 \mathrm{kDa}$ protein was related to the proteinase, they would compete for antibody binding. Fig. $6 b$ shows the disappearance of the band in lane 3 and 4 , where 1 and $10 \mu \mathrm{g}$, respectively, of purified unlabelled proteinase were used in competition. In lane
2, no proteinase was added and a distinct band of $54 \mathrm{kDa}$ was observed. Two negative controls were used. The $54 \mathrm{kDa}$ band was not seen when mRNA from AS-grown cells was translated and immunoprecipitated (lane 1). In lane 5, immunoprecipitates of translation products of mRNA from BSA-grown cells with pre-immune serum were loaded. As expected, the $54 \mathrm{kDa}$ band was not seen. It was therefore clear that $54 \mathrm{kDa}$ protein was antigenically related to proteinase. Since the band was seen only in translation products of RNA from induced cells, it was very likely to be the pre-protein of the proteinase.

\section{Proteinase repression by ammonium salts}

Proteinase secretion was repressed when ammonium sulphate was added to either M1 or M2-BSA culture. Ammonium acetate and ammonium chloride could also repress proteinase secretion. The effect of addition of 


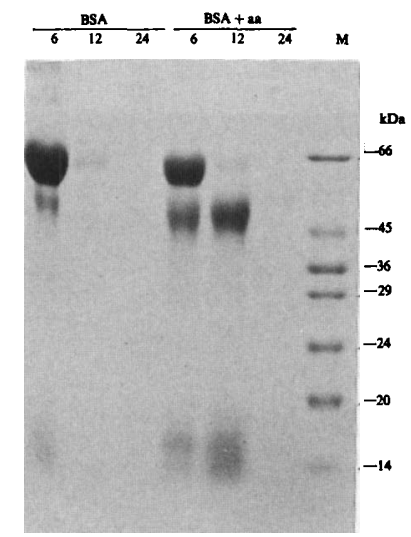

Fig. 7. Degradation of BSA during proteinase induction. CS of cultures grown with BSA or BSA and amino acid mixture (equivalent to amino acid composition of BSA) were analysed by $12 \%$ (w/v) SDSPAGE (Coomassie Blue stain); $10 \mu \mathrm{l}$ samples taken at 6, 12, and $24 \mathrm{~h}$ were analysed. $M$ is the protein molecular mass marker (Sigma). ammonium sulphate to a BSA culture was studied by Western blot anlaysis. Adding ammonium sulphate to a $12 \mathrm{~h} \mathrm{M}$ 2-BSA culture caused the proteinase level to decrease progressively, and $24 \mathrm{~h}$ after addition, very little proteinase was seen (data not shown). In a control M2BSA culture, which was incubated for a similar period undisturbed, the proteinase was present at the fully induced level. When the $\mathrm{pH}$ of the medium was checked $24 \mathrm{~h}$ after addition of ammonium sulphate, it was found to be about 1.9 ; the $\mathrm{pH}$ of the medium containing only ammonium sulphate was about 1.8 , and in the medium containing only BSA the $\mathrm{pH}$ was $4 \cdot 2$. Growth on ammonium sulphate appears to lower the $\mathrm{pH}$ of the medium, making the proteinase very unstable. Moreover, the low $\mathrm{pH}$ of the medium may prevent further secretion of proteinase either directly or indirectly. To find out if ammonium sulphate is directly inhibiting proteinase activity, purified proteinase was incubated

(a)

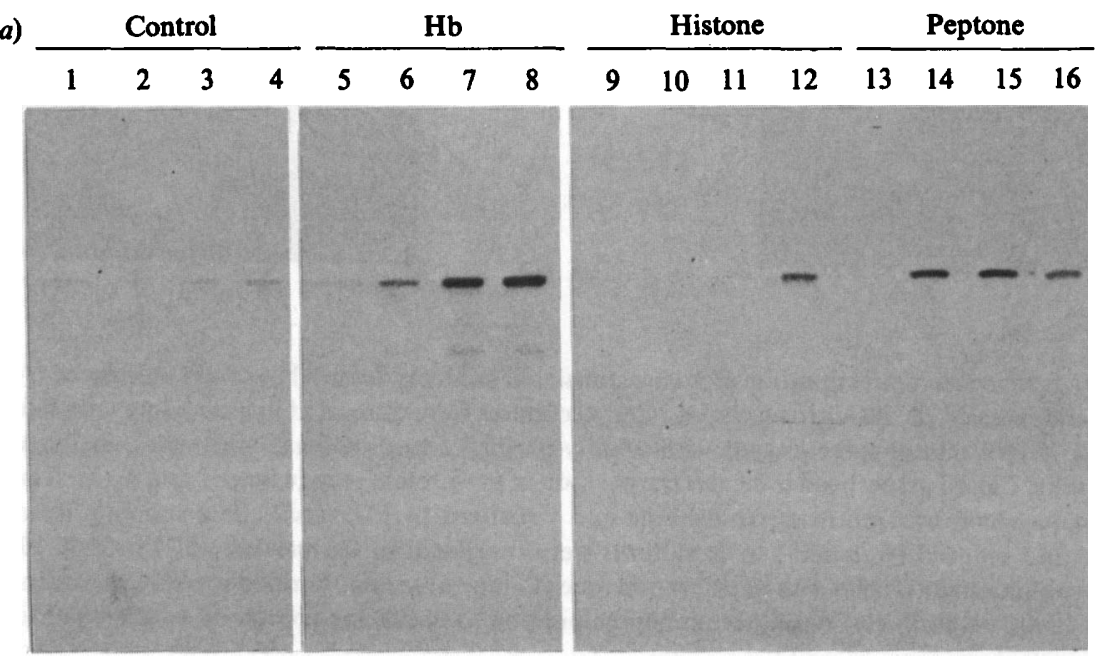

(b)
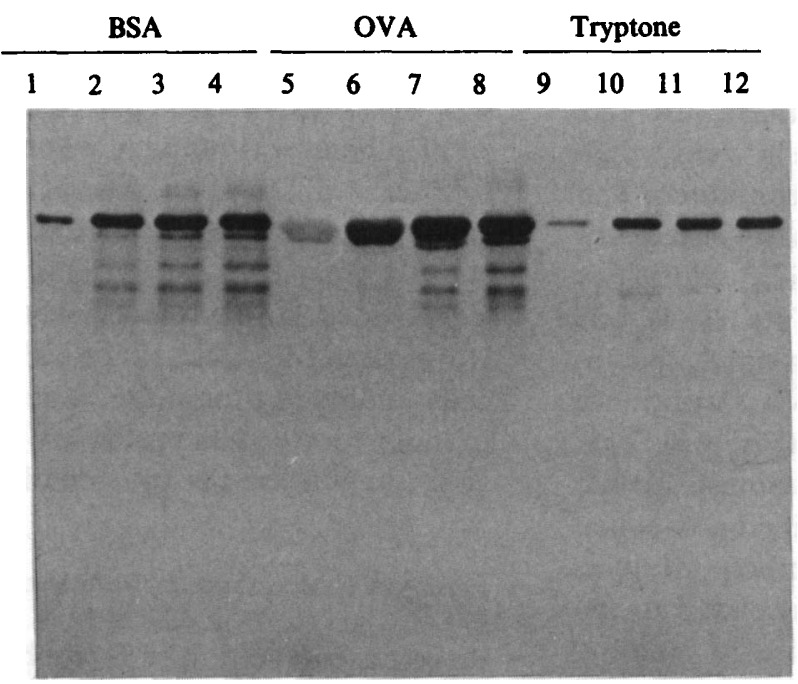

Fig. 8. Proteinase induction by various inducers. Five $\mu$ l of each CS collected at $6,12,24$ and $48 \mathrm{~h}$ were analysed by Western blot using affinity-purified anti-proteinase antibodies. (a) Lanes 1 to 4, without any inducer; lanes 5 to 8, haemoglobin; lanes 9 to 12, histone; lanes 13 to 16 , peptone. (b) Lanes 1 to 4 , BSA; lanes 5 to 8 , ovalbumin; lanes 9 to 12 , tryptone. 
with $0.2 \%$ ammonium sulphate at room temperature for $4 \mathrm{~h}$; there was no loss in activity (monitored by milk agarose assay; data not shown).

When an amino acid mixture, prepared according to the composition of BSA, was added to M2-BSA culture, both BSA degradation and proteinase induction were delayed (Fig. 7). Furthermore, when ammonium sulphate was added to M2-BSA culture, neither proteinase secretion nor BSA degradation was seen. It appears therefore that free nitrogen sources, such as ammonium salts and amino acids, repress the induction and secretion of proteinase.

\section{Proteinase inducers}

BSA and a few other proteins (e.g. ovalbumin, haemoglobin, histone and casein) were tested as substrates for proteinase in the spectrophotometric assay. Haemoglobin was the most efficiently degraded substrate (data not shown). When the same set of proteins and peptone (Difco), and tryptone (Difco) were used at $0.2 \%$, as a nitrogen source, all could induce proteinase, but the proteinase level varied, depending on the inducer. CS samples from the induced cultures collected at different times were also analysed by Western blotting (Fig. 8). BSA, haemoglobin, and ovalbumin were efficient inducers, while histone, tryptone, and peptone were poor. Peptides present in tryptone and peptone probably serve as inducers. Casamino acids, or an amino acid mixture prepared according to the composition of BSA, did not induce proteinase (data not shown). These results suggest that proteinase is induced and secreted into the culture medium when the nitrogen source is limited to proteins and peptides, not amino acids. Further work is in progress to understand the basic mechanism of induction under nitrogen-restricted conditions.

Note added in proof. Recently, putative genes encoding secretory acid proteinase have been cloned by us (Ganesan, K., Banerjee, A. \& Datta, A. 1991. Infection and Immunity 59, in the Press) and by others (Hube, B., Turver, C. J., Odds, F. C., Eiffert, H., Boulnois, G. J., Kochel, H. \& Ruchel, R. 1991. Journal of Medical and Veterinary Mycology 29, 129132). The sequence reported by Hube et al. (1991) indicates that the proteinase is synthesized as a precursor with a putative signal peptide consisting of $\mathbf{5 0}$ amino acids. This is consistent with our report of a preprotein for secretory acid proteinase identified by in-vitro translation and immunoprecipitation of RNA from BSA-induced cells.

This work was supported by a grant from the Department of Science and Technology, Ministry of Science and Technology, New Delhi, India.

\section{References}

ANDERSON, D. J. \& BLOBEL, G. (1983). Immunoprecipitation of proteins from cell free translations. Methods in Enzymology 96, 111-120.
Ausubel, F. M., Brent, R., Kingston, R. E., Moore, D. D., Seidman, J. G., SMIth, J. A. \& STRuHL, K. (1987). Current Protocols in Molecular Biology. New York: Green Publishing Associates and Wiley-Interscience.

Chamberlain, J. P. (1979). Fluorographic detection of radioactivity in polyacrylamide gels with the water-soluble fluor, sodium salicylate. Analytical Biochemistry 98, 132-135.

ChomczYNSKI, P. \& SACCHI, N. (1987). Single step method of RNA isolation by acid guanidium thiocyanate-phenol-chloroform extraction. Analytical Biochemistry 162, 156-159.

Foltmann, B., Szecsi, P. B. \& Tarasova, N. I. (1985). Detection of proteases by clotting of casein after gel electrophoresis. Analytical Biochemistry 146, 353-360.

HEREFORD, L. M. \& ROSBASH, M. (1977). Number and distribution of polyadenylated RNA sequences in yeasts. Cell 10, 453-462.

IWAKI, T., KUME-IWAKI, A., LIEM, R. K. H. \& GoldMan, J. E. (1989). $\alpha \mathrm{B}-$ Crystallin is expressed in non-lenticular tissues and accumulates in Alexander's disease brain. Cell 57, 71-78.

KESSLER, S. W. (1981). Use of protein A-bearing Staphylococci for the immunoprecipitation and isolation of antigens from cells. Methods in Enzymology 73, 442-458.

LAEMMLI, U. K. (1970). Cleavage of structural proteins during the assembly of the head of the bacteriophage T4. Nature, London 227 , 680-685.

MACDONALD, F. \& ODDs, F. C. (1980). Inducible proteinase of Candida albicans in diagnostic serology and in the pathogenesis of systemic candidosis. Journal of Medical Microbiology 13, 423-435.

Maniatis, T., Fritsch, E. F. \& Sambroox, J. (1982). Molecular Cloning : a Laboratory Manual, Cold Spring Harbor NY: Cold Spring Harbor Laboratory.

NASH, B. \& TATE, S. S. (1984). In vitro translation and processing of rat kidney $\gamma$-glutamyl transpeptidase. Journal of Biological Chemistry 259, 678-685.

ODDs, F. C. (1988). Candida and Candidosis, 2nd edn. London: Bailliere Tindall.

Randall, L. L., Hardy, S. J. S. \& Thom, J. R. (1987). Export of a protein: a biochemical view. Annual Review of Microbiology 41, 507-541.

RAY, T. L. \& PAYNE, C. D. (1990). Comparative production and rapid purification of Candida acid proteinase from protein supplemented cultures. Infection and Immunity 58, 508-514.

Remold, H., Fasold, H. \& Staib, F. (1968). Purification and characterization of a proteolytic enzyme from Candida albicans. Biochimica et Biophysica Acta 167, 399-406.

Ross, I. K., De Bernardis, F., Emerson, G. W., Cassone A. \& Sullivan, P. A. (1990). The secreted aspartate proteinase of Candida albicans: physiology of secretion and virulence of a proteinasedeficient mutant. Journal of General Microbiology 136, 687-694.

RUCHEL, R. (1981). Properties of a purified proteinase from the yeast Candida albicans. Biochimica et Biophysica Acta 659, 99-113.

Ruchel, R., UhlemanN, K. \& BonING, B. (1983). Secretion of acid proteinases by different species of the genus Candida. Zentralblatt fur Bakteriologie, Mikrobiologie und Hygiene (Abteilung I) 255, 537-548.

RUCHEL, R., BONING, B. \& BoRG, M. (1986). Characterization of a secretory proteinase of Candida parapsilosis and evidence for the absence of enzyme during infection in vitro, Infection and Immunity $53,411-419$.

SCHUMACHER, G. F. B. \& Schull, W. B. (1972). Radial diffusion in gel for microdetermination of enzymes. II. Plasminogen activator, elastase, and non-specific proteases. Analytical Biochemistry 48, 9-26.

ShImizU, K., KondoH, Y. \& TaNaKA, K. (1987). Proteinase production and pathogenicity of Candida albicans. I. Invasion into chorioallantoic membrane by $C$. albicans strains of different proteinase activity. Microbiology and Immunology 31, 1045-1060.

StalB, F. (1969). Proteolysis and pathogenicity of Candida albicans strains. Mycopathologica et Mycologia Applicata 37, 345-348.

Towbin, H., StakHelin, T. \& GoRDON, J. (1979). Electrophoretic transfer of proteins from polyacrylamide gels to nitrocellulose sheets: procedure and some applications. Proceedings of the National Academy of Sciences of the United States of America 76, 4350-4354. 